\title{
Monitoring Sulfur Content in Marine Fuel Oil Using Ultraviolet Imaging Technology
}

\author{
Zhenduo Zhang ${ }^{1}$, Wenbo Zheng ${ }^{1}$, Ying $\mathrm{Li}^{1, *}$, Kai Cao ${ }^{1, *}$, Ming Xie ${ }^{1}$ (D) and Peng $\mathrm{Wu}^{2}$ \\ 1 Navigation College, Dalian Maritime University, Dalian 116026, China; zhangzhenduo@dlmu.edu.cn (Z.Z.); \\ zwb123456789@dlmu.edu.cn (W.Z.); mingxie@dlmu.edu.cn (M.X.) \\ 2 Collage of Geoexploraton Science and Technology, Jilin University, Jilin 130026, China; \\ wupeng20@mails.jlu.edu.cn \\ * Correspondence: yldmu@dlmu.edu.cn (Y.L.); caokai@dlmu.edu.cn (K.C.)
}

check for updates

Citation: Zhang, Z.; Zheng, W.; Li, Y.; Cao, K.; Xie, M.; Wu, P. Monitoring Sulfur Content in Marine Fuel Oil Using Ultraviolet Imaging

Technology. Atmosphere 2021, 12, 1182. https: / / doi.org/10.3390/ atmos12091182

Academic Editors: Wengang Mao,

Anastassia Baxevani and

Nicolas Raillard

Received: 23 July 2021

Accepted: 6 September 2021

Published: 14 September 2021

Publisher's Note: MDPI stays neutral with regard to jurisdictional claims in published maps and institutional affiliations.

Copyright: (c) 2021 by the authors. Licensee MDPI, Basel, Switzerland. This article is an open access article distributed under the terms and conditions of the Creative Commons Attribution (CC BY) license (https:// creativecommons.org/licenses/by/ $4.0 /)$.

\begin{abstract}
The emission of $\mathrm{SO}_{2}$ from ships is an important source of atmospheric pollution. Therefore, the International Maritime Organization (IMO) has established strict requirements for the sulfur content of marine fuel oil. In this paper, a new optical noncontact detection technique for ship exhaust emissions analysis is studied. Firstly, the single-band simulation analysis model of the imaging detection technology for $\mathrm{SO}_{2}$ concentration in ship exhaust gas and the deep neural network model for the prediction of sulfur content were established. A bench test was designed to monitor the tail gas concentration simultaneously using online and imaging detection methods, so as to obtain the concentration data in the flue and the ultraviolet image data. The results showed that $300 \mathrm{~nm}$ had a higher inversion accuracy than the other two bands. Finally, a deep neural network model was trained with the $\mathrm{SO}_{2}$ concentration data from the inversion and the engine power, and the predictive model of sulfur content in marine fuel oil was thereby obtained. When the deep learning model was used to predict sulfur content, the prediction accuracy at 300,310, and $330 \mathrm{~nm}$ was $73 \%$, $94 \%$, and $71 \%$, respectively.
\end{abstract}

Keywords: ship emissions; exhaust plume; $\mathrm{SO}_{2}$ concentration; deep learning; imaging detection

\section{Introduction}

With the unstoppable tide of economic globalization and the advent of the 21st-century "Maritime Silk Road", shipping has become the most important mode of transportation in global trade due to its large cargo volume and low freight, providing a strong guarantee for the rapid and steady development of the global economy [1]. However, as ships travel on oceans and rivers far away from cities, we do not have a direct perception of the exhaust pollution caused by ships, so governments and researchers around the world do not pay enough attention such pollution [2]. Since the 1980s, the Maritime Environmental Protection Committee (MEPC) of the International Maritime Organization (IMO) has been committed to improving the problem of exhaust pollution caused by ships. In 1997, according to the principle of Article 15 of the Rio Declaration on Environment and Development, the MEPC of the IMO formulated Annex VI of the 1973 International Convention for the Prevention of Pollution from Ships (MARPOL73/78)—Rules for the Prevention of Air Pollution from Ships [3].

On the global scale, approximately $15 \%$ of $\mathrm{NO}_{\mathrm{x}}$ emissions and $4-9 \%$ of $\mathrm{SO}_{2}$ emissions are caused by the shipping industry [4]. Nearly $70 \%$ of the exhaust gas is discharged into the maritime atmosphere less than $400 \mathrm{~km}$ away from land, which causes serious air pollution in coastal areas, especially around the ports with heavy cargo traffic [5-9]. Furthermore, the proportion of ship exhaust emissions in global total air pollutant emissions is increasing every year, partly due to shipping trade growth, but mainly because other industries have implemented better regulatory measures that have effectively reduced the emissions of land-based exhaust pollutants. 
The sulfur contained in ship fuel oil results in the production of a large amount of $\mathrm{SO}_{2}$ through chemical reactions occurring during engine operation, and the amount of $\mathrm{SO}_{2}$ discharged is directly related to the sulfur content of fuel oil [10]. Marine heavy fuel oil has a sulfur content of $3.5 \%$, and its color is jet black. Marine heavy fuel oil is mostly "intermediate fuel oil" or "residual oil", which has adhesive properties and produces a large number of toxic and harmful substances if it is not burned sufficiently. The sulfur content of automotive oil in line with the standard is $0.001 \%$; its color is clear and transparent, with good antiexplosion characteristics and low corrosivity. The sulfur content of marine fuel oil conforming to the ECA standard is $0.1 \%$ [11]. Its color is reddish-brown but clear without impurities, and the combustion products are relatively clean and environmentally friendly. By comparing the three types of fuel, it is easy to envision the environmental harm caused by marine heavy fuel oil. Moreover, due to the huge oil consumption of ships, if a ship with 50,000 deadweight tons uses heavy oil as fuel, the amount of sulfur dioxide emitted every day is equivalent to the total amount emitted by 210,000 trucks.

At present, there are two main methods to measure ship exhaust: the first is to directly measure the plume via a helicopter or unmanned aerial vehicle carrying a sniffer; the second is to detect ship exhaust with ultraviolet differential absorption spectroscopy (DOAS) systems mounted on helicopters or lighthouse buoys [12]. The first method has the advantage of measuring the plume directly, so the instrument is highly accurate and flexible when mounted on a helicopter or drone platform [13]. However, the drawbacks of this method are also very obvious. The flight altitude of the helicopter or unmanned aerial vehicle (UAV) needs to be 25 to $50 \mathrm{~m}$ from the ship's chimney to effectively measure the exhaust content of the ship, and at this altitude the aircraft will seriously affect the normal navigation of the ship. They also need to stay in the plume for 15 to $20 \mathrm{~s}$. Since the ship is sailing normally, the aircraft must maintain a low speed and stable flight, and cannot effectively measure tail gas in the optimal plume sampling area at all times. In addition, the measuring position of the sniffer is not at the ship's smokestack opening. The temperature and tail gas concentration decrease significantly with distance from the opening, and further interference can be caused by various meteorological conditions. Thus, the detection accuracy was shown to be low in the real port environment, which needed to be corrected by using the measured data from several flights [14]. The advantage of the second method is that it does not affect the normal navigation of the ship through long-distance detection [15]. The disadvantage of DOAS is that the selected band needs to have an obvious peak-valley structure, and the peak-valley bands must to be close to each other to reduce the interference from other gases. For the accuracy of gas concentration inversion results, the peak and valley bands need to be extremely precise. The simple use of a narrow band filter cannot meet the precision requirements, and it must be coordinated with the spectrometer [16]. DOAS uses spectrometers for band separation and accepts exhaust concentration throughout the ship's area [17]. The concentration of exhaust gas at the mouth of a ship's chimney cannot be accurately measured because it cannot be imaged. The imaging detection technique proposed by Prata [18] at the Norwegian Institute for Air Research can overcome this defect. In addition, imaging detection equipment is relatively cheap, and easy to operate and carry. Imaging detection technology inverts $\mathrm{SO}_{2}$ concentration with 2D imaging information in images, and multiple tail plume images can be collected every second. As a result, imaging detection technology can retain the temporal and spatial variation characteristics successfully [19].

Beecken J et al. [20] developed an exhaust gas detection system that uses a sniffer carried by small aircraft to measure $\mathrm{SO}_{2}, \mathrm{NO}_{\mathrm{x}}$, and particulate matter emitted by ships. The system has a quick response measurement capability of $1 \mathrm{~Hz}$, with an uncertainty of approximately $20 \%$ for $\mathrm{SO}_{2}$ and $24 \%$ for $\mathrm{NO}_{x}$. Premuda $\mathrm{M}$ et al. [21] proposed the fluid rate emission method with DOAS (FRE-DOAS), which is used to evaluate the emission of pollutants from moving sources such as ships. Loov JMB et al. [22] used DOAS to determine the sulfur content and $\mathrm{NO}_{\mathrm{x}}$ emission factor of ship fuel at the Port of Rotterdam and compared it with the ship exhaust data directly measured from the chimney mouth 
on the passenger ship Stena Hollandica. Although optical methods can provide reliable results, the sniffer method is the most convenient technique for remote determination of $\mathrm{SO}_{2}$ and $\mathrm{NO}_{\mathrm{x}}$ emission factors. Fan $\mathrm{Z}$ et al. [23] designed a new UAV system that consists of a movement control terminal, a video acquisition terminal, a small pod carrying a sniffer, and a rotating UAV. It realizes the real-time, efficient, and accurate detection of $\mathrm{SO}_{2}$ and $\mathrm{NO}_{2}$ in ship exhaust gas. Compared with the traditional sniffer method, it can reduce the errors due to exhaust diffusion to a certain extent. However, it only provides a new method with respect to the design of the UAV system, which cannot completely eliminate the errors inherent in the measurement method. Duan W et al. [24], based on the ultraviolet absorption of $\mathrm{SO}_{2}$ in the $310 \mathrm{~nm}$ band, designed a new monitoring technique for measuring two-dimensional $\mathrm{SO}_{2}$ distribution through theoretical analysis, and adopted an ultraviolet imaging technology with double filter channels to obtain separate signal images and background images. In this method, UV imaging and DOAS were used to collect $\mathrm{SO}_{2}$ concentration information, and the concentration information obtained showed good consistency.

In this study, the spectral characteristics of $\mathrm{SO}_{2}$ in ship exhaust were evaluated. A single-wavelength imaging detection simulation analysis of the concentration of $\mathrm{SO}_{2}$ in ship exhaust gas was carried out, and the single-wavelength inversion errors in $\mathrm{SO}_{2}$ concentration in three bands at 300, 310, and $330 \mathrm{~nm}$ were analyzed. In addition, a system of noncontact optical monitoring equipment for ship exhaust gas was presented that could analyze ship exhaust gases quickly at a long distance. The ship exhaust emission monitoring was carried out using optical monitoring equipment. At the same time, online monitoring equipment was used to directly obtain the real ship exhaust data. The UV image data were processed by a complete data-processing method, and the concentration of $\mathrm{SO}_{2}$ was retrieved by a single-band inversion model. Combined with the deep-learning method, the predictive model of sulfur content in marine fuel oil was constructed. The results showed that $310 \mathrm{~nm}$ UV could be used to predict fuel sulfur content with the highest accuracy, reaching $94 \%$. This study provides a theoretical basis for the establishment of a ship exhaust emission monitoring system.

\section{Methods}

\subsection{Single-Wavelength Simulation Analysis Model}

The law of light absorption, also known as the Lambert-Beer law, is the theory of the quantitative analysis of the absorption effect of all light-absorbing substances, including molecules, atoms, ions, solids, liquids, and gases, on all electromagnetic radiation. The law of light absorption is expressed as follows [25]:

$$
I(\lambda)=I_{0}(\lambda) \exp \left[-L\left(c_{S_{2}} \sigma_{S_{O_{2}}}(\lambda)+\sum_{i=1}^{n} \sigma(\lambda) c_{i}\right)+\varepsilon_{R}+\varepsilon_{M}\right]
$$

where $I_{0}$ is the initial light intensity; $I$ is the light intensity received by the optical system after passing through the absorbing gas; $L$ is the optical path length; $\lambda$ is the wavelength; $c_{\mathrm{SO}_{2}}$ is the $\mathrm{SO}_{2}$ concentration; $\sigma_{\mathrm{SO}_{2}}(\lambda)$ is the $\mathrm{SO}_{2}$ absorption cross-section for the given wavelength; $c_{i}$ is the concentration of the other absorbing gases, excluding $\mathrm{SO}_{2} ; \sigma_{i}(\lambda)$ is the absorption cross-section of the other absorbing gases; $n$ is the number of the other types of absorbing gases; $\varepsilon_{R}$ is the Rayleigh scattering; and $\varepsilon_{M}$ is the Mie scattering.

In addition to the absorption effect of $\mathrm{SO}_{2}, \mathrm{NO}_{2}$ also has an obvious absorption cross-section in ship exhaust between $280 \mathrm{~nm}$ and $380 \mathrm{~nm}$, as shown in Figure 1. 


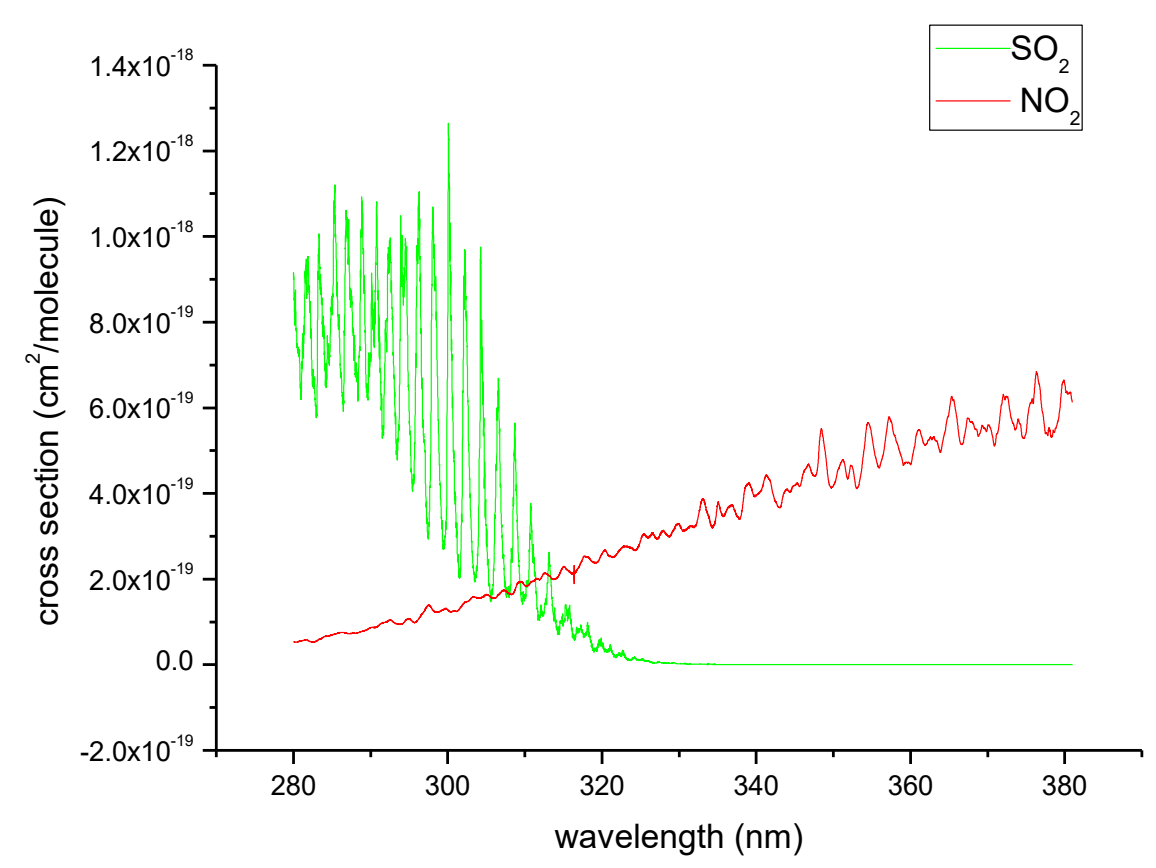

Figure 1. $\mathrm{SO}_{2}$ and $\mathrm{NO}_{2}$ absorption cross-sections (data source: the HITRAN 2016 molecular spectroscopic database [26]).

In this study, only the influence of $\mathrm{NO}_{2}$ was considered, and the influence of scattering was ignored. Beecken J et al. [20] showed that between $15 \%$ and $50 \%$ of the NO emitted by ships is transformed into $\mathrm{NO}_{2}$, and the specific value depends on the distance from the emission source. However, for the exhaust gas just out of the chimney mouth, the NO conversion rate may not reach $15 \%$. Therefore, this study carried out a simulation analysis for 15 cases in which the NO conversion rate varied from $1 \%$ to $15 \%$. The simulation analysis model was as follows:

$$
I(\lambda)=I_{0}(\lambda) \exp \left[-L\left(c_{S_{2}} \sigma_{\mathrm{SO}_{2}}(\lambda)+c_{\mathrm{NO}_{2}} \sigma_{\mathrm{NO}_{2}}(\lambda)\right)\right]
$$

According to Equation (2), the formula for calculating the $\mathrm{SO}_{2}$ concentration can be expressed as follows after ignoring other gas absorption effects:

$$
c_{\mathrm{SO}_{2}}=\left[I_{0}(\lambda) / I(\lambda)\right] /[L \sigma(\lambda)]
$$

The $\mathrm{SO}_{2}$ absorption cross-sections of the three bands obtained from the High-Resolution Transmission Molecular Spectroscopy Database (HITRAN) were $\sigma(300 \mathrm{~nm})=3.868 \times 10^{-19}$ $\mathrm{cm}^{2} /$ molecule, $\sigma(310 \mathrm{~nm})=1.6134 \times 10^{-19} \mathrm{~cm}^{2} /$ molecule, and $\sigma(330 \mathrm{~nm})=4.797 \times 10^{-21}$ $\mathrm{cm}^{2} /$ molecule. In the previously stated form of the Lambert-Beer law, the unit of concentration of $\mathrm{SO}_{2}$ was $\mathrm{m}^{2} / \mathrm{g}$, so a unit conversion is required. The conversion formula is:

$$
\sigma_{\mathrm{m}^{2} / \mathrm{g}}=\frac{0.0001 \mathrm{~m}^{2} / \mathrm{cm}^{2} * \sigma_{\mathrm{cm}^{2} / \text { molecule }}}{1.063 \times 10^{-22} \mathrm{~g} / \text { molecule }}
$$

As calculated by Equation (4), $\sigma_{300}=0.363876 \mathrm{~m}^{2} / \mathrm{g}, \sigma_{310}=0.15178 \mathrm{~m}^{2} / \mathrm{g}$, and $\sigma_{330}=0.0045127 \mathrm{~m}^{2} / \mathrm{g}$. In the ship exhaust monitoring experiment, the diameter of the chimney was $0.8 \mathrm{~m}$. Therefore, the three single-wavelength $\mathrm{SO}_{2}$ concentration inversion models can be respectively expressed as:

$$
c_{300}=3.435236 \times \ln \left[\frac{I_{0}(300)}{I(300)}\right]
$$




$$
\begin{aligned}
& c_{310}=8.235604 \times \ln \left[\frac{I_{0}(300)}{I(300)}\right] \\
& c_{330}=276.996 \times \ln \left[\frac{I_{0}(300)}{I(300)}\right]
\end{aligned}
$$

Three error indicators; namely, root mean square error (RMSE), mean absolute error (MAE), and mean absolute percentage error (MAPE), were used to evaluate the accuracy of the $\mathrm{SO}_{2}$ concentration calculation. The calculation methods of the three error indicators are presented below:

$$
\begin{gathered}
\text { MAE }=\frac{1}{k} \sum_{i=1}^{k}\left|c_{\text {true }}-c_{\text {forecast }}\right| \\
\text { RMSE }=\sqrt{\frac{1}{k} \sum_{i=1}^{k}\left|c_{\text {true }}-c_{\text {forecast }}\right|^{2}} \\
\text { MAPE }=\frac{1}{k} \sum_{i=1}^{k}\left|\frac{c_{\text {true }}-c_{\text {forecast }}}{c_{\text {true }}}\right| \times 100 \%
\end{gathered}
$$

where $c_{\text {true }}$ is the true $\mathrm{SO}_{2}$ concentration; $c_{\text {forecast }}$ is the predicted $\mathrm{SO}_{2}$ concentration; and $k$ is the number of the groups of collected concentration data.

\subsection{Deep Neural Network Model}

Based on the $\mathrm{SO}_{2}$ concentration obtained by inversion, a predictive model of sulfur content in ship oil was established using deep learning. However, the $\mathrm{SO}_{2}$ concentration in ship exhaust will vary not only with fuel sulfur content, but also with engine power [27]. Thus, we needed to take the engine power into account. The sulfur content prediction model adopted the $\mathrm{SO}_{2}$ concentration obtained from the inversion of the single-wavelength inversion model and the power of the main engine as the inputs to predict four different sulfur contents. The schematic diagram of the sulfur content prediction model is shown in Figure 2 below. Four types of marine fuel oil with sulfur contents of $0.1 \%, 0.3 \%, 0.5 \%$ and $0.8 \%$ were used in the experiment. Thus, the final output was one of the four sulfur contents.

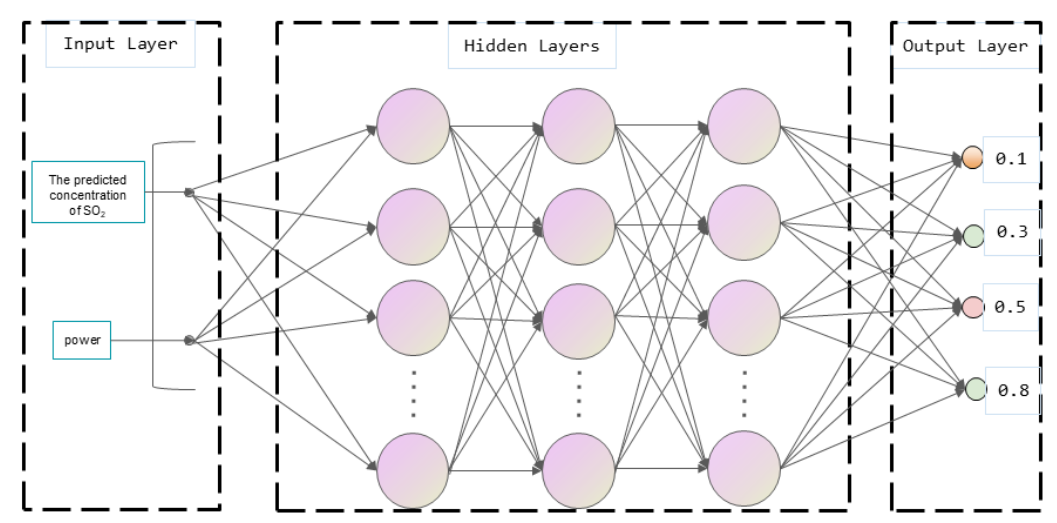

Figure 2. The schematic diagram of the sulfur content prediction model.

\section{Experiments and Data}

A bench experiment utilizing UV imaging was performed to obtain the ship emission data closest to the actual situation and UV image data. Four types of fuel with a sulfur content ranging from 0.1 to $0.8 \%$ and 13 different engine power conditions ranging from 0 to $100 \%$ were used for this experiment. An online monitoring system was used to collect the gas concentration data by punching a hole in the flue, and UV imaging detection equipment was used to collect ultraviolet image data from the ship's exhaust. 


\subsection{Experimental Diesel Engine}

A MAN B\&W 6S35ME-B9 diesel engine in Figure 3 was the main engine used in the bench experiment. It is an electronically controlled two-stroke six-cylinder cross-head-type ship main engine with $3400 \mathrm{~kW}$ power, $142 \mathrm{r} / \mathrm{min}$ rated speed, 3.5\% allowable maximum marine fuel sulfur content, and 30,000 $\mathrm{kg} / \mathrm{h}$ approved maximum tail gas handling capacity.

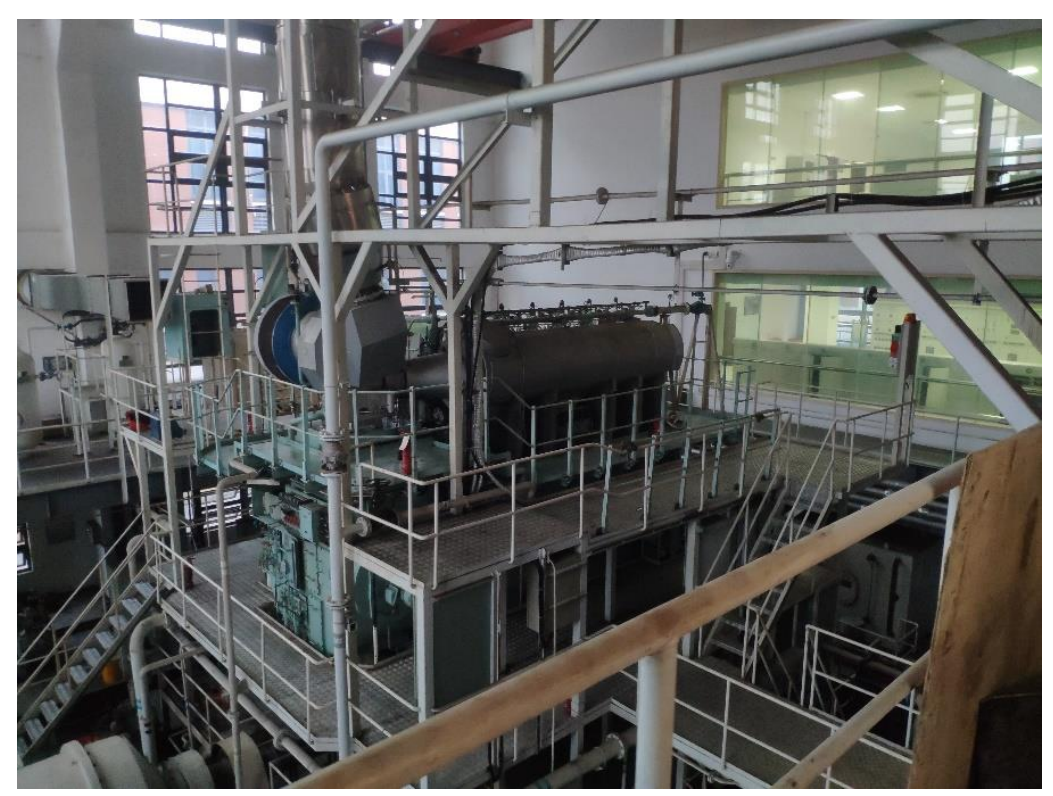

Figure 3. Ship diesel engine selected for the experiment.

\subsection{Online Monitoring Equipment}

The sampling probe was placed in the center of the ship flue, and the real concentration of exhaust pollutants was determined by direct sampling of flue gas by using the ship exhaust online monitoring equipment. The connection between the sampling probe and the flue is shown in Figure 4.

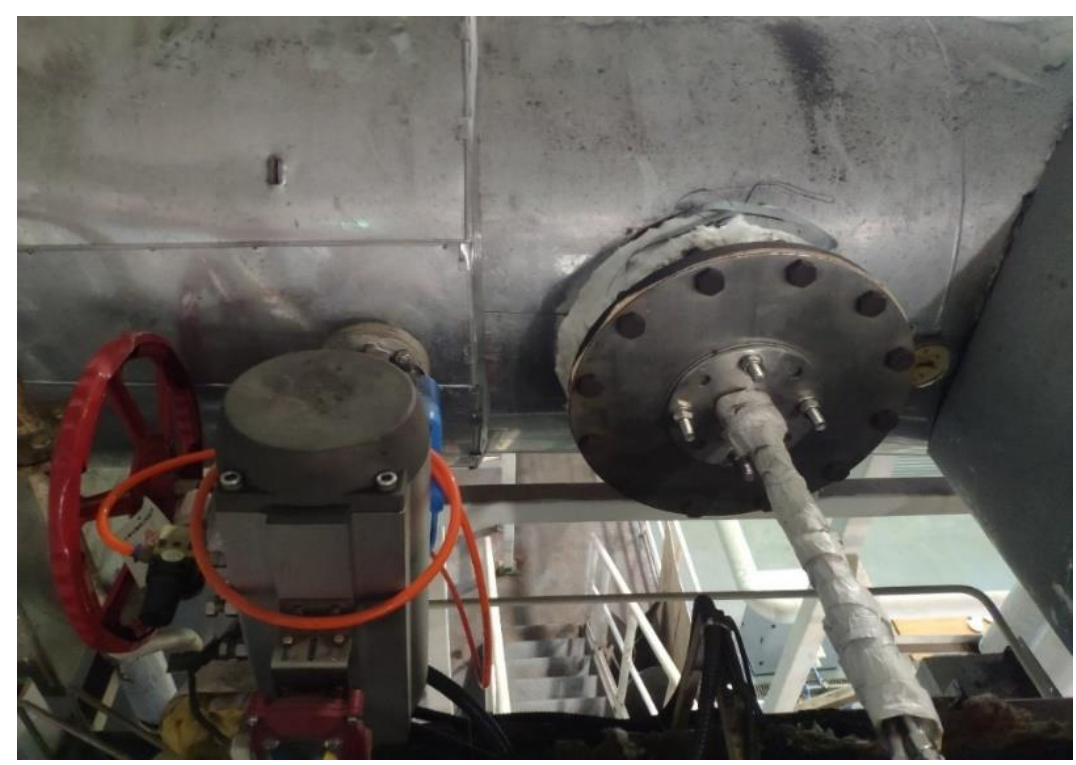

Figure 4. Sampling port of the chimney channel.

An RJ-CEMD ship exhaust online monitoring system was selected; this system conforms to the MARPOL Annex VI and IMO-MEPC technical regulations on ship exhaust emissions. 


\subsection{Marine Fuel}

Four types of marine fuel with sulfur contents of $0.1 \%, 0.3 \%, 0.5 \%$, and $0.8 \%$ were used in the experiment. These were thought to be representative of the sulfur content in actual marine fuels used during navigation and berthing.

\subsection{Working Conditions of the Diesel Engine}

When marine fuel with the same sulfur content was used, the different working conditions of the diesel engine yielded the primary effect on the ship exhaust. Table 1 shows the different working conditions of the diesel engine.

Table 1. Diesel engine conditions employed in the experiment.

\begin{tabular}{cccccccccccccc}
\hline Number & 1 & 2 & 3 & 4 & 5 & 6 & 7 & 8 & 9 & 10 & 11 & 12 & 13 \\
\hline Power percentage (\%) & 0 & 5 & 10 & 15 & 20 & 25 & 30 & 40 & 50 & 60 & 80 & 90 & 100 \\
\hline
\end{tabular}

\subsection{UV Imaging Detection Equipment}

The ultraviolet imaging detection equipment used in this experiment is shown in Figure 5. The equipment had optical filter and measurement functions, and the spectral induction band was $230-920 \mathrm{~nm}$. The working environment temperature range was -20 to $50{ }^{\circ} \mathrm{C}$; the resolution was $2048 \times 2048$; the data bit depth was 16-bit; the focal length was $78 \mathrm{~mm}$; and the lens size was $50 \mathrm{~mm}$.

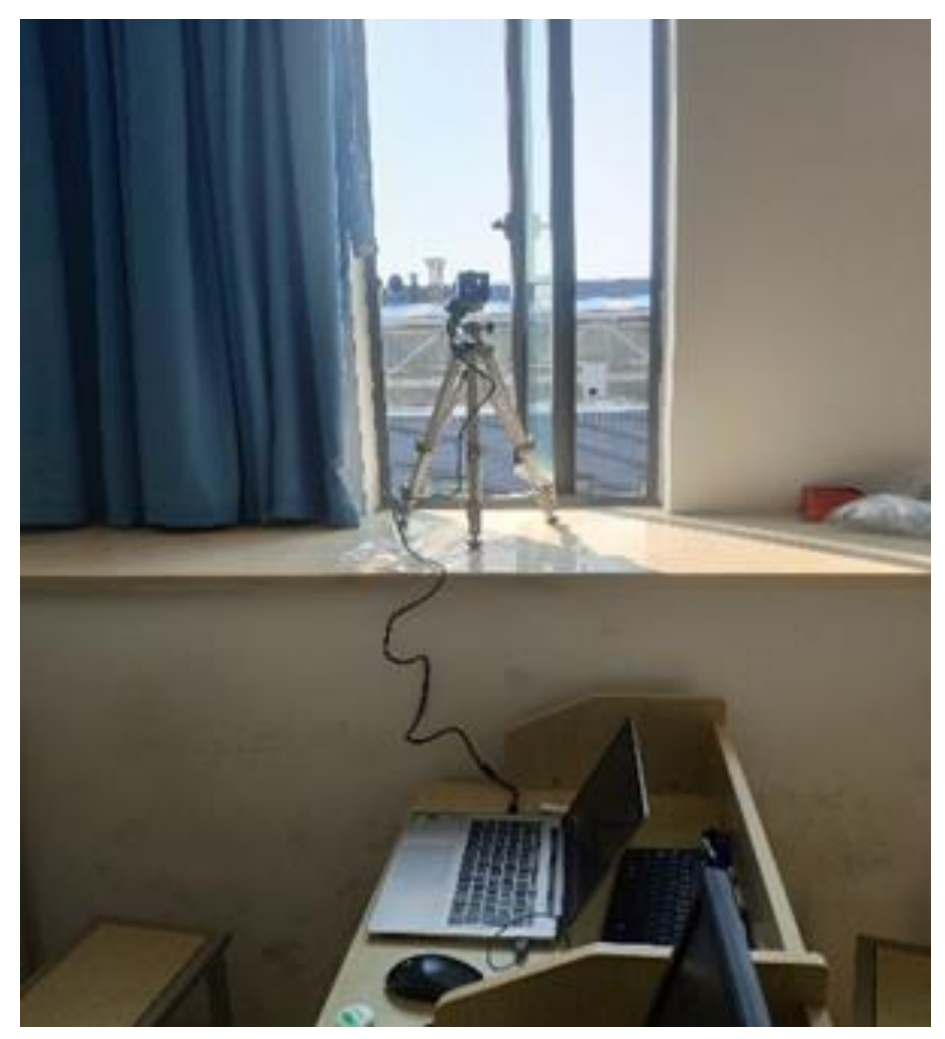

Figure 5. UV detection equipment for plume sampling.

In order to minimize noise in the ultraviolet image and retain the detail of the image to the maximum extent, an adaptive fuzzy median filtering algorithm was used to filter the image. A square area with side lengths equal to $2 / 5$ of the chimney diameter was selected for the extraction of ship exhaust. In order to ensure that $\mathrm{SO}_{2}$ concentration was extracted from the same exhaust gas area in each image, a Canny edge-extraction algorithm was utilized to automatically extract the chimney boundary of each image, and then the location of ship exhaust gas area was found. The gray value in the extraction area was 
averaged and the background value subtracted to obtain the optical thickness needed to invert the concentration of $\mathrm{SO}_{2}$.

\section{Results and Discussion}

\subsection{Single-Wavelength Simulation Analysis Results}

The collected gas concentration data were substituted into Equation (2) for the simulation, and then Equations (5)-(7) were used to obtain the respective inverted $\mathrm{SO}_{2}$ concentrations. The single-wavelength simulation analysis results for different $\mathrm{NO}$ conversion rates at different wavelengths are shown in Figure 6.
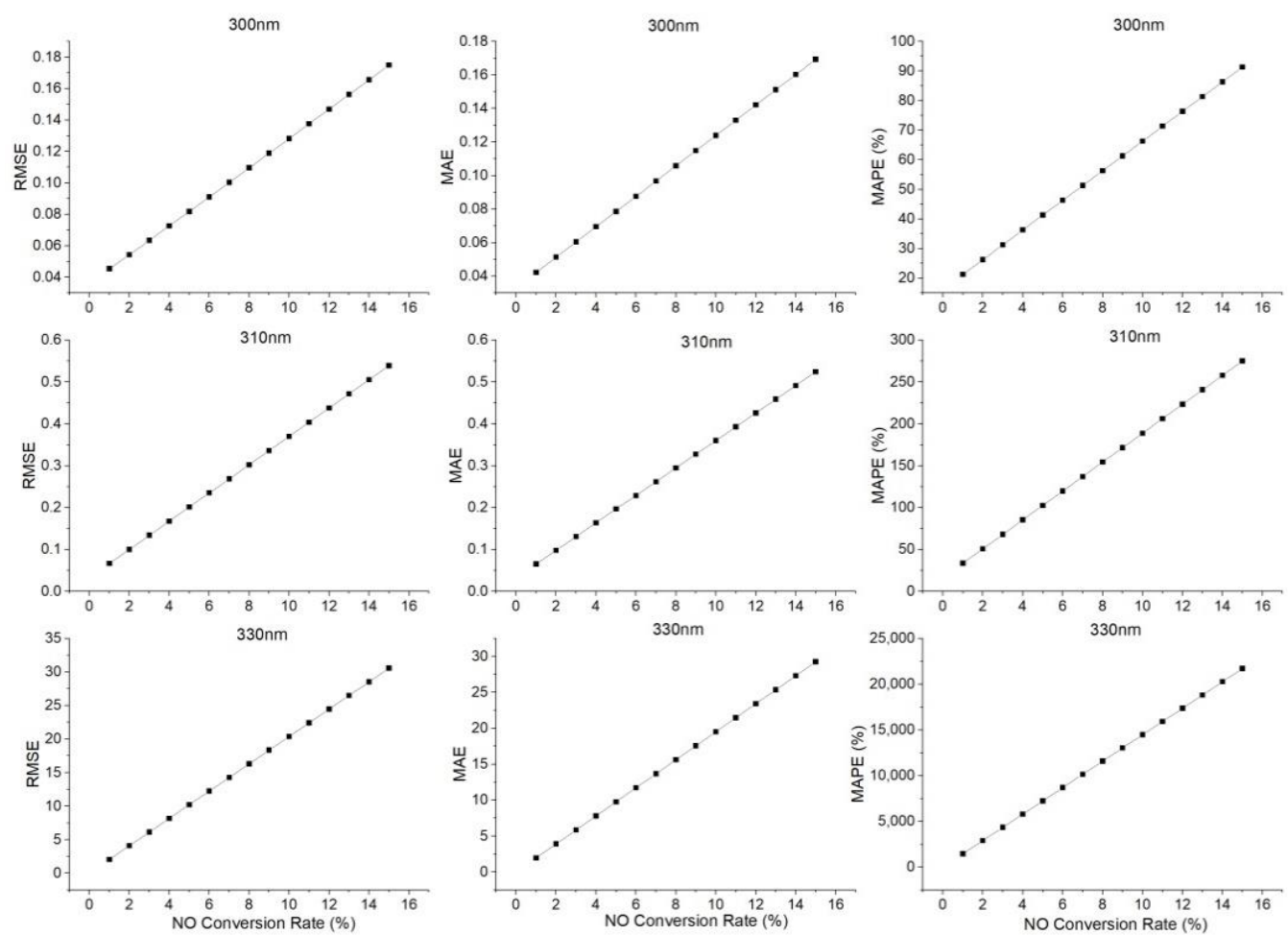

Figure 6. Single-wavelength simulation analysis results for different NO conversion rates at different wavelengths.

When the tail gas was discharged from the flue, with the increase of the NO conversion rate, the interference from $\mathrm{NO}_{2}$ was continuously enhanced, leading to the continuous increase of single-wavelength simulation errors. When the NO conversion rate was constant, the simulation errors at $300 \mathrm{~nm}$ were the smallest, because compared with the other two bands, the absorption of $\mathrm{SO}_{2}$ at $300 \mathrm{~nm}$ was stronger, while the interference from $\mathrm{NO}_{2}$ was smaller.

\subsection{Single-Wavelength Inversion Results of Ultraviolet Images}

Equations (5)-(7) were used to invert the collected ultraviolet images to obtain $\mathrm{SO}_{2}$ concentration. The $\mathrm{SO}_{2}$ concentration inversion results obtained from ultraviolet images at the three wavelengths are shown in Figures 7-9. 


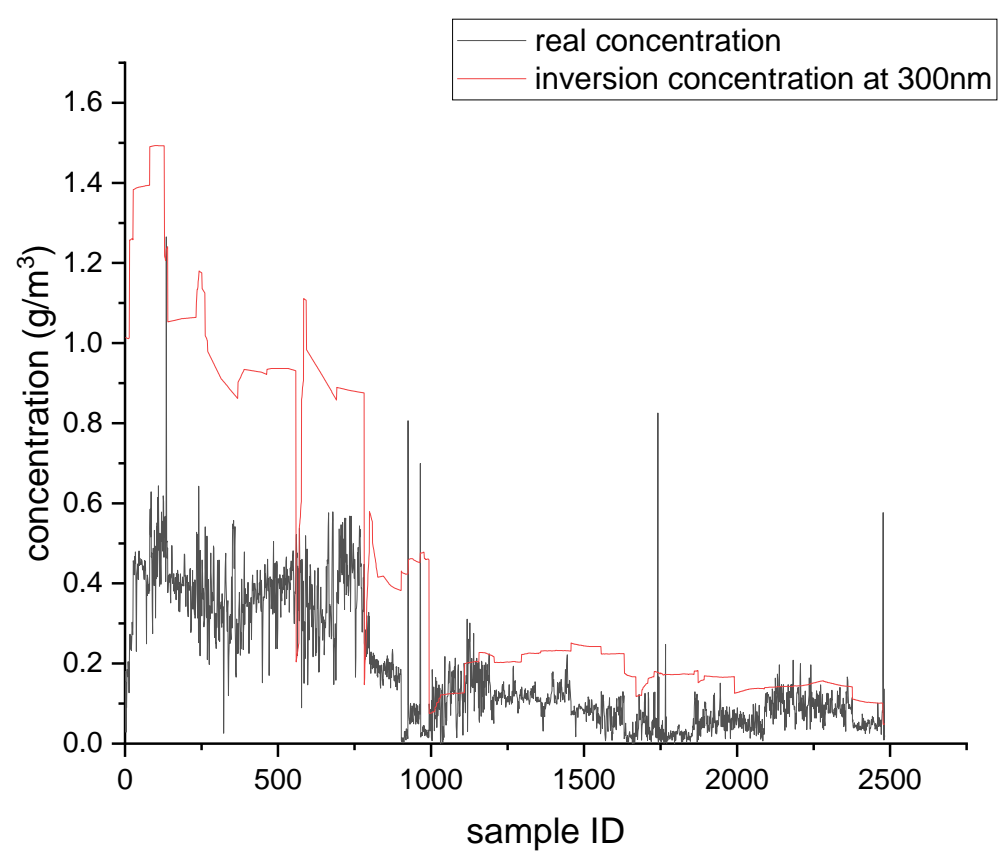

Figure 7. Single-wavelength inversion results at $300 \mathrm{~nm}$.

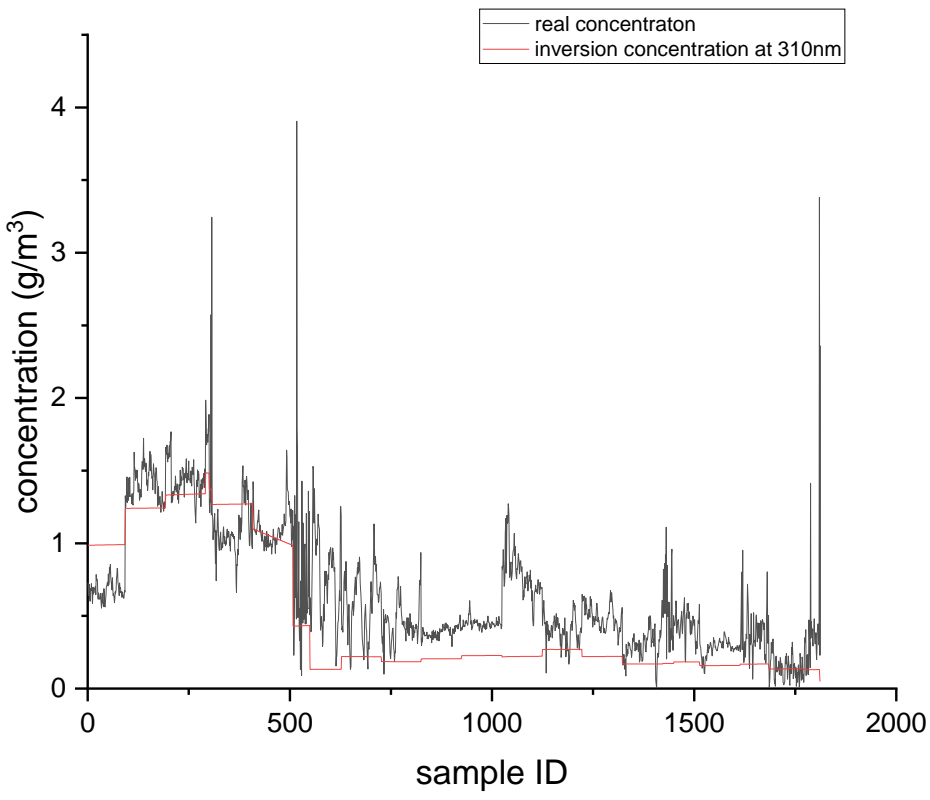

Figure 8. Single-wavelength inversion results at $310 \mathrm{~nm}$.

The errors in $\mathrm{SO}_{2}$ concentration inversion using UV images at the three wavelengths are shown in Table 2.

Table 2. $\mathrm{SO}_{2}$ concentration inversion errors at three UV wavelengths.

\begin{tabular}{cccc}
\hline Wavelength $(\mathbf{n m})$ & RMSE & MAE & MAPE \\
\hline 300 & 0.15 & 0.12 & 55.69 \\
310 & 0.38 & 0.28 & 148.28 \\
330 & 15.43 & 13.20 & 9976.35 \\
\hline
\end{tabular}




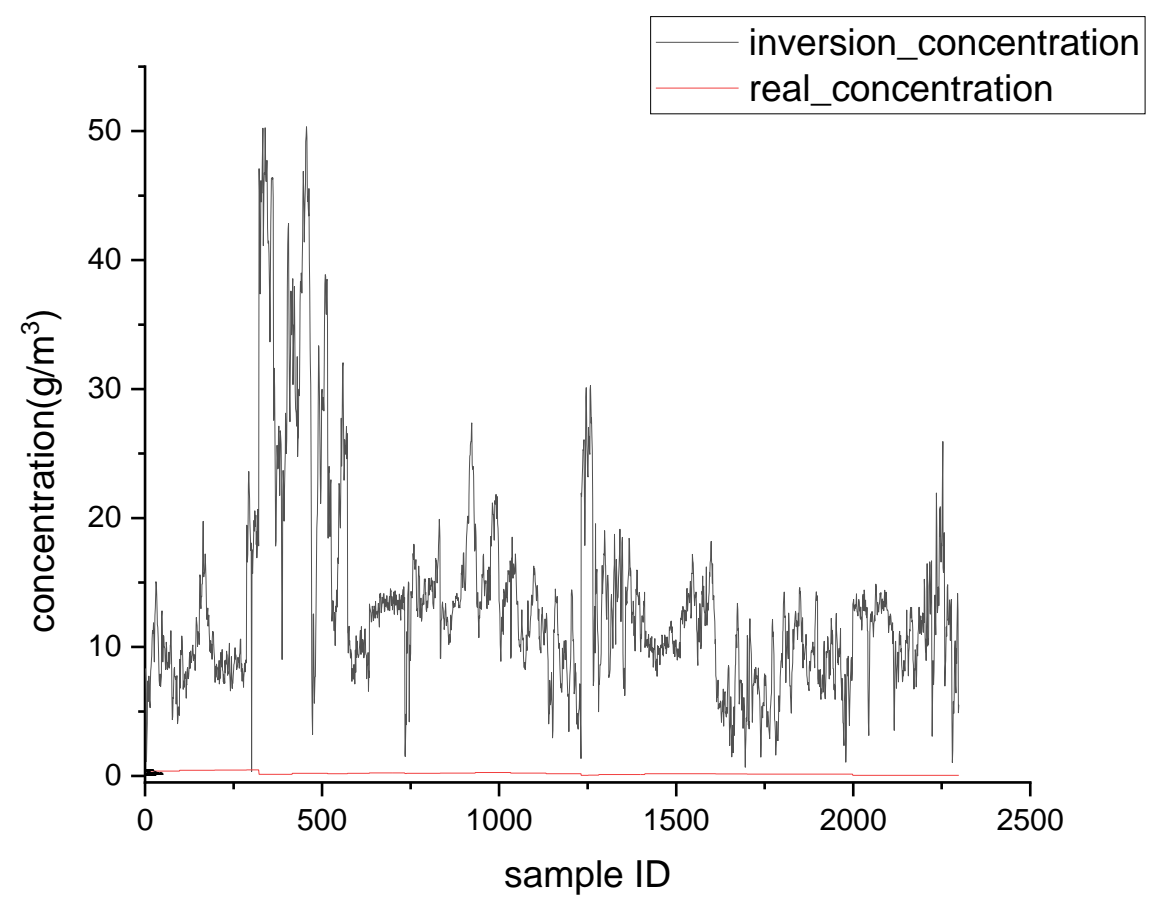

Figure 9. Single-wavelength inversion results at $330 \mathrm{~nm}$.

As shown in Table 2, when the actual image was used for single-wavelength inversion, the minimum inversion errors occurred at $300 \mathrm{~nm}$, which was consistent with the simulation results. This also was consistent with the fact that the absorption of $\mathrm{SO}_{2}$ was the strongest at $300 \mathrm{~nm}$, and the interference from $\mathrm{NO}_{2}$ was the lowest at $300 \mathrm{~nm}$.

By comparing the inversion results obtained from UV images with the simulation results, the conversion rate of $\mathrm{NO}$ just discharged from the chimney mouth was estimated to be approximately $7-8 \%$. Regardless of the simulation results or the UV image inversion results, the errors at $330 \mathrm{~nm}$ were very large. This is because the absorption of $\mathrm{SO}_{2}$ at $330 \mathrm{~nm}$ was very weak, while the interference factors such as absorption of $\mathrm{NO}_{2}$ and scattering were very influential. In general, $330 \mathrm{~nm}$ is used as the reference channel in dual-wavelength inversion, and interference factors that do not change with wavelength are subtracted out, so as to obtain more accurate $\mathrm{SO}_{2}$ concentration data. In this experiment, the real gas concentration was the gas concentration in the flue, while the UV image data collected was at the chimney mouth. Since it was impossible to know the dilution degree of the gas just coming out of the chimney mouth, it was assumed that the concentration of the gas just coming out of the flue mouth remained unchanged. In reality, the gas concentration at the flue mouth was lower than that in the flue. It can be seen from the inversion results for the three wavelengths that if the real $\mathrm{SO}_{2}$ concentration was lowered, the inversion results at $300 \mathrm{~nm}$ were closer to the true value. Although $300 \mathrm{~nm}$ had the smallest inversion errors among the three wavelengths, it also had the highest requirement for skylight conditions in practical application. In the case of poor skylight background, the signal-to-noise ratio of a UV image acquired at $300 \mathrm{~nm}$ may be low, making the UV image data unusable. When the sulfur content was $0.1 \%$, the concentration of $\mathrm{SO}_{2}$ in the tail gas was low, and because the sensitivity of the detector used in this experiment was limited, most of the images collected at 300 and $310 \mathrm{~nm}$ could not be used due to low signal-to-noise ratios. However, at $330 \mathrm{~nm}$, perhaps due to strong absorption of other gases and scattering, more effective data could be obtained. In future work, it will be necessary to consider the solar zenith angle, the transmittance curve of the filter, and other related factors, and to analyze the inversion errors of $\mathrm{SO}_{2}$ concentration, the signal-to-noise ratio of the image, and other factors, so as to obtain the optimal detection wavelength for UV imaging technology. 


\subsection{Sulfur Content Prediction Results}

Precision, recall, F1-score, accuracy, macro avg., and weighted avg. of the models were obtained by training with the data at the three respective wavelengths. The deep-learning results for the three wavelengths are shown in Tables 3-5.

Table 3. Model evaluation report for $300 \mathrm{~nm}$.

\begin{tabular}{cccccc}
\hline Fuel Sulfur Content $(\mathbf{\%} \mathbf{~ m} / \mathbf{m})$ & Counts & Precision & Recall & F1-Score & Accuracy \\
\hline 0.1 & 4 & 0 & 0 & 0 & - \\
0.3 & 806 & 0.71 & 0.81 & 0.76 & - \\
0.5 & 676 & 0.74 & 0.69 & 0.72 & - \\
0.8 & 212 & 0.81 & 0.57 & 0.66 & - \\
Macro avg. & 1698 & 0.57 & 0.52 & 0.54 & - \\
Weighted avg. & 1698 & 0.74 & 0.73 & 0.73 & - \\
Total & 1698 & - & - & - & 0.73 \\
\hline
\end{tabular}

Table 4. Model evaluation report for $310 \mathrm{~nm}$.

\begin{tabular}{cccccc}
\hline Fuel Sulfur Content $(\% \mathbf{~ m} / \mathbf{m})$ & Counts & Precision & Recall & F1-Score & Accuracy \\
\hline 0.1 & 2 & 1 & 0.5 & 0.67 & - \\
0.3 & 388 & 0.91 & 0.93 & 0.92 & - \\
0.5 & 873 & 0.97 & 0.94 & 0.96 & - \\
0.8 & 42 & 0.69 & 0.9 & 0.78 & - \\
Macro avg. & 1305 & 0.89 & 0.82 & 0.83 & - \\
Weighted avg. & 1305 & 0.94 & 0.94 & 0.94 & - \\
Total & 1305 & - & - & - & 0.94 \\
\hline
\end{tabular}

Table 5. Model evaluation report for $330 \mathrm{~nm}$.

\begin{tabular}{cccccc}
\hline Fuel Sulfur Content $(\% \mathbf{~ m} / \mathbf{m})$ & Counts & Precision & Recall & F1-Score & Accuracy \\
\hline 0.1 & 300 & 0.49 & 0.49 & 0.49 & - \\
0.3 & 767 & 0.74 & 0.83 & 0.78 & - \\
0.5 & 910 & 0.81 & 0.76 & 0.79 & - \\
0.8 & 321 & 0.60 & 0.53 & 0.56 & - \\
Macro avg. & 2298 & 0.66 & 0.65 & 0.65 & - \\
Weighted avg. & 2298 & 0.71 & 0.71 & 0.71 & - \\
Total & 2298 & - & - & - & 0.71 \\
\hline
\end{tabular}

The prediction accuracy of sulfur content at $310 \mathrm{~nm}$ was the highest, reaching $94 \%$. This indicated that the single-wavelength $\mathrm{SO}_{2}$ inversion model combined with the deeplearning method could be used to accurately predict the sulfur content of ship fuel. The accuracy at $310 \mathrm{~nm}$ was the highest, possibly because the distribution characteristics of $\mathrm{SO}_{2}$ inversion data at $310 \mathrm{~nm}$ conformed to the distribution characteristics of sulfur content, which was more easily learned by the deep neural network.

\section{Conclusions}

In this study, we performed a simulation experiment of ship exhaust emissions, built a single-wavelength simulation analysis model, and established a predictive model of sulfur content in ship fuel oil. The single-wavelength simulation analysis model could predict $\mathrm{SO}_{2}$ concentration with high accuracy from an ultraviolet image of the exhaust plume taken by a UV camera. The predictive model of sulfur content resulted in the effective prediction of sulfur content of ship fuel oil. The results showed that the prediction accuracy of sulfur content was the highest at $310 \mathrm{~nm}$, reaching $94 \%$. This work proved the feasibility of using $\mathrm{UV}$ absorption characteristics of $\mathrm{SO}_{2}$ to invert $\mathrm{SO}_{2}$ concentration and then predict sulfur content in marine fuel oil combined with engine power. Our method could predict 
FSC without obtaining $\mathrm{CO}_{2}$ or a model of the fuel consumption. This method could reduce the complexity of the equipment. As a result, the method is easy to use for marine fuel oil compliance inspection. In this paper, only the single-wavelength ship exhaust imaging detection method was studied. In future research, dual-wavelength ship exhaust imaging detection experiments will be carried out to establish a dual-wavelength ship exhaust $\mathrm{SO}_{2}$ concentration prediction model, so as to provide more accurate $\mathrm{SO}_{2}$ concentration prediction results. Furthermore, the deep neural network will be further improved to enhance the prediction accuracy of sulfur content in marine fuel oil.

Author Contributions: Conceptualization, Z.Z. and W.Z.; methodology, Z.Z.; software, W.Z.; validation, Y.L., K.C. and M.X.; formal analysis, P.W.; investigation, K.C.; resources, Z.Z.; data curation, W.Z.; writing—original draft preparation, Z.Z.; writing—review and editing, Z.Z., W.Z., K.C., Y.L., M.X., P.W.; visualization, K.C.; supervision, Y.L.; project administration, Y.L.; funding acquisition, Y.L., M.X. and K.C. All authors have read and agreed to the published version of the manuscript.

Funding: This study was supported financially by the Fundamental Research Funds for the Central Universities (3132021137), Postdoctoral Science Foundation of China (2020M670730) and National Natural Science Foundation of China (52101398).

Institutional Review Board Statement: Not applicable.

Informed Consent Statement: Not applicable.

Data Availability Statement: The data and codes that support the findings of this paper is available at the corresponding authors upon reasonable request.

Conflicts of Interest: The authors declare no conflict of interest.

\section{References}

1. Jalkanen, J.P.; Johansson, L.; Kukkonen, J. A comprehensive inventory of ship traffic exhaust emissions in the European sea areas in 2011. Atmos. Chem. Phys. 2016, 16, 71-84. [CrossRef]

2. International Maritime Organization. Reduction of GHG Emissions from Ships Third IMO GHG Study 2014-Final Report; MEPC.: London, UK, 2014; Volume 67.

3. International Maritime Organization (IMO). Annex VI of MARPOL 73/78, Regulations for the Prevention of Air Pollution from Ships and NOx Technical Code; IMO: London, UK, 2007; Volume 3, pp. 154-196.

4. $\quad$ Eyring, V.; Isaksen, I.S.A.; Berntsen, T.; Collins, W.J.; Corbett, J.J.; Endresen, O.; Grainger, R.G.; Moldanova, J.; Schlager, H.; Stevenson, D.S. Transport impacts on atmosphere and climate: Shipping. Atmos. Environ. 2010, 44, 4735-4771. [CrossRef]

5. Zhao, J.; Fan, J.; Zhang, B.; Shi, Y. Satellite remote-sensing monitoring technology and the research advances of $\mathrm{SO}_{2}$ in the atmosphere. J. Saf. Environ. 2012, 4, 166-169.

6. Yan, H.; Chen, L.; Tao, J.; Han, D.; Su, L.; Yu, C. SO 2 long-term monitoring by satellite in the Pearl River Delta. J. Remote Sens. 2012, 2, 390-404.

7. Huaxiang, S.; Minhua, Y. Effectiveness evaluation of $\mathrm{SO}_{2}$ emission reduction in Guizhou Province. Earth Environ. 2014, 5, 319-327.

8. Huaxiang, S.; Minhua, Y. Analysis on effectiveness of $\mathrm{SO}_{2}$ emission reduction in Guangxi Zhuang Autonomous Region by satellite remote sensing. Chin. J. Environ. Eng. 2015, 3, 1361-1368.

9. Li, B.; Ju, T.; Zhang, B.; Ge, J.; Zhang, J.; Tang, H. Satellite remote sensing monitoring and analysis of the causes of temporal and spatial variation characteristics of atmospheric $\mathrm{SO}_{2}$ Concentration in Tianshui. Environ. Monit. China 2016, 2, 134-140.

10. Li, C. Emissions Characteristics and Future Trends of Non-Road Mobile Sources in China. Ph.D. Thesis, South China University of Technology, Guangzhou, China, 2017.

11. Mellqvist, J.; Conde, V.; Beecken, J.; Ekholm, J. Surveillance of Sulfur Emissions from Ships in Danish Waters; Chalmers University of Technology: Göteborg, Sweden, 2017.

12. Daniel, A.B.; Carmen, R.M.B. Bridge-based sensing of $\mathrm{NOx}$ and $\mathrm{SO}_{2}$ emissions from ocean-going ships. Atmos. Environ. 2016, 136, 54-60.

13. Zhou, F.; Pan, S.; Chen, W.; Ni, X.; An, B. Monitoring of compliance with fuel sulfur content regulations through unmanned aerial vehicle (UAV) measurements of ship emissions. Atmos. Meas. Tech. 2019, 12, 6113-6124. [CrossRef]

14. Anand, A.; Wei, P.; Gali, N.K.; Sun, L.; Yang, F.; Westerdahl, D.; Zhang, Q.; Deng, Z.; Wang, Y.; Liu, D.; et al. Protocol development for real-time ship fuel sulfur content determination using drone based plume sniffing microsensor system. Sci. Total Environ. 2020, 744, 140885. [CrossRef]

15. Seyler, A.; Wittrock, F.; Kattner, L.; Mathieu-Üffing, B.; Peters, E.; Richter, A.; Schmoke, S.; Burrows, J.P. Monitoring shipping emissions in the German Bight using MAX-DOAS measurements. Atmos. Chem. Phys. 2017, 17, 10997-11023. [CrossRef]

16. Berg, N.; Mellqvist, J.; Jalkanen, J.P.; Balzani, J. Ship emissions of $\mathrm{SO}_{2}$ and $\mathrm{NO}_{2}$ : DOAS measurements from airborne platforms. Atmos. Meas. Tech. 2012, 5, 1085-1098. [CrossRef] 
17. Cheng, Y.; Wang, S.; Zhu, J.; Guo, Y.; Zhang, R.; Liu, Y.; Zhang, Y.; Yu, Q.; Ma, W.; Zhou, B. Surveillance of $\mathrm{SO}_{2}$ and $\mathrm{NO}_{2}$ from ship emissions by MAX-DOAS measurements and implication to compliance of fuel sulfur content. Atmos. Chem. Phys. 2019, 19, 13611-13626. [CrossRef]

18. Prata, A.J. Measuring $\mathrm{SO}_{2}$ ship emissions with an ultraviolet imaging camera. Atmos. Meas. Tech. 2014, 7, 1213-1229. [CrossRef]

19. Osorio, M.; Casaballe, N.; Belsterli, G.; Barreto, M.; Gomez, A.; Ferrari, J.A.; Frins, E. Plume segmentation from UV camera images for $\mathrm{SO}_{2}$ emission rate quantification on cloud days. Remote. Sens. 2017, 9, 517. [CrossRef]

20. Beecken, J.; Mellqvist, J.; Salo, K.; Ekholm, J.; Jalkanen, J.-P. Airborne emission measurements of $\mathrm{SO}_{2}$, $\mathrm{NOx}$ and particles from individual ships using a sniffer technique. Atmos. Meas. Tech. 2014, 7, 1957-1968. [CrossRef]

21. Premuda, M.; Masieri, S.; Bortoli, D.; Kostadinov, I.; Petritoli, A.; Giovanelli, G. Evaluation of vessel emissions in a lagoon area with ground based Multi axis DOAS measurements. Atmos. Environ. 2011, 45, 5212-5219. [CrossRef]

22. Balzani Lööv, J.M.; Alfoldy, B.; Gast, L.F.L.; Hjorth, J.; Lagler, F.; Mellqvist, J.; Beecken, J.; Berg, N.; Duyzer, J.; Westrate, H.; et al. Field test of available methods to measure remotely SOx and Nox emissions from ships. Atmos. Meas. Tech. 2014, 7, $2597-2613$. [CrossRef]

23. Zhou, F.; Gu, J.; Chen, W.; Ni, X. Measurement of $\mathrm{SO}_{2}$ and $\mathrm{NO}_{2}$ in ship plumes using rotary unmanned aerial system. Atmosphere 2019, 10, 657. [CrossRef]

24. Duan, W.; Xiong, Y.; Chen, Z.; Yu, G.; Liu, L.; Li, F.; Wu, K. Remote sensing and monitoring of industrial $\mathrm{SO}_{2}$ and carbon black particles with ultraviolet imaging technology. Acta Photonica Sin. 2020, 49, 153-161.

25. Zhang, Z.; Zheng, W.; Cao, K.; Li, Y.; Xie, M. Simulation analysis on the optimal imaging detection wavelength of $\mathrm{SO}_{2}$ concentration in ship exhaust. Atmosphere 2020, 11, 1119. [CrossRef]

26. Gordon, I.E.; Rothman, L.S.; Hill, C.; Kochanov, R.V.; Tan, Y.; Bernath, P.F.; Birk, M.; Boudon, V.; Campargue, A.; Chance, K.V.; et al. The HITRAN 2016 molecular spectroscopic database. J. Quant. Spectrosc. Radiat. Transf. 2017, 203, 3-69. [CrossRef]

27. Cao, K.; Zhang, Z.; Li, Y.; Zheng, W.; Xie, M. Ship fuel sulfur content prediction based on convolutional neural network and ultraviolet camera images. Environ. Pollut. 2021, 273, 116501. [CrossRef] 